\title{
Seasonality of the particle number concentration and size distribution: a global analysis retrieved from the network of Global Atmosphere Watch (GAW) near-surface observatories
}

5 Clémence Rose ${ }^{1}$, Martine Collaud Coen ${ }^{2}$, Elisabeth Andrews ${ }^{3,4}$, Yong Lin ${ }^{5}$, Isaline Bossert ${ }^{1,6}$, Cathrine Lund Myhre ${ }^{5}$, Thomas Tuch ${ }^{7}$, Alfred Wiedensohler ${ }^{7}$, Markus Fiebig ${ }^{5}$, Pasi Aalto ${ }^{8}$, Andrés Alastuey ${ }^{9}$, Elisabeth Alonso-Blanco ${ }^{10}$, Marcos Andrade ${ }^{11}$, Begoña Artíñano ${ }^{10}$, Todor Arsov ${ }^{12}$, Urs Baltensperger ${ }^{13}$, Susanne Bastian ${ }^{14}$, Olaf Bath ${ }^{15}$, Johan Paul Beukes ${ }^{16}$, Benjamin T. Brem ${ }^{13}$, Nicolas Bukowiecki ${ }^{13, *}$, Juan Andrés Casquero-Vera ${ }^{17,18}$, Sébastien Conil ${ }^{19}$, Konstantinos Eleftheriadis ${ }^{20}$, Olivier Favez ${ }^{21}$, Harald 10 Flentje $^{22}$, Maria I. Gini ${ }^{20}$, Francisco Javier Gómez-Moreno ${ }^{10}$, Martin Gysel-Beer ${ }^{13}$, A. Gannet Hallar ${ }^{23}$, Ivo Kalapov ${ }^{12}$, Nikos Kalivitis ${ }^{24}$, Anne Kasper-Giebl ${ }^{25}$, Melita Keywood ${ }^{26}$, Jeong Eun Kim ${ }^{27}$, Sang-Woo $\mathrm{Kim}^{28}$, Adam Kristensson ${ }^{29}$, Markku Kulmala ${ }^{8}$, Heikki Lihavainen ${ }^{30,31}$, Neng-Huei Lin ${ }^{32,33}$, Hassan Lyamani $^{17,18}$, Angela Marinoni ${ }^{34}$, Sebastiao Martins Dos Santos ${ }^{35}$, Olga L. Mayol-Bracero ${ }^{36}$, Frank Meinhardt ${ }^{15}$, Maik Merkel ${ }^{7}$, Jean-Marc Metzger ${ }^{37}$, Nikolaos Mihalopoulos ${ }^{24,38}$, Jakub Ondracek ${ }^{39}$, Marco

15 Pandolfii $^{9}$, Noemi Pérez ${ }^{9}$, Tuukka Petäjä ${ }^{8}$, Jean-Eudes Petit ${ }^{40}$, David Picard ${ }^{1}$, Jean-Marc Pichon ${ }^{1}$, Veronique Pont ${ }^{41}$, Jean-Philippe Putaud ${ }^{35}$, Fabienne Reisen ${ }^{26}$, Karine Sellegri ${ }^{1}$, Sangeeta Sharma ${ }^{42}$, Gerhard Schauer $^{43}$, Patrick Sheridan ${ }^{4}$, James Patrick Sherman ${ }^{44}$, Andreas Schwerin ${ }^{15}$, Ralf Sohmer ${ }^{15}$, Mar Sorribas $^{45}$, Junying Sun ${ }^{46}$, Pierre Tulet ${ }^{47}$, Ville Vakkari ${ }^{16,30}$, Pieter Gideon van Zyl ${ }^{16}$, Fernando Velarde ${ }^{11}$, Paolo Villani ${ }^{48}$, Stergios Vratolis ${ }^{20}$, Zdenek Wagner ${ }^{39}$, Sheng-Hsiang Wang ${ }^{32}$, Kay Weinhold ${ }^{7}$, Rolf

20 Weller $^{49}$, Margarita Yela ${ }^{45}$, Vladimir Zdimal ${ }^{39}$ and Paolo Laj ${ }^{50,34,8}$

${ }^{1}$ Université Clermont Auvergne, CNRS, Laboratoire de Météorologie Physique (LaMP), F-63000 Clermont-Ferrand, France.

${ }^{2}$ Federal Office of Meteorology and Climatology, MeteoSwiss, Payerne, Switzerland

${ }^{3}$ Cooperative Institute for Research in Environmental Sciences, University of Colorado, Boulder, CO, USA

${ }^{4}$ NOAA Global Monitoring Laboratory, Boulder, CO, USA

$25{ }^{5}$ NILU-Norwegian Institute for Air Research, Kjeller, Norway

${ }^{6}$ Université Bourgogne Franche Comté, Besançon, France

${ }^{7}$ Leibniz Institute for Tropospheric Research, Leipzig, Germany

${ }^{8}$ Institute for Atmospheric and Earth System Research, University of Helsinki, Helsinki, Finland

${ }^{9}$ Institute of Environmental Assessment and Water Research (IDAEA), Spanish Research Council (CSIC), Barcelona, Spain

${ }^{10}$ CIEMAT, Center for Research on Energy, Environment and Technology, Joint Research Unit CSIC-CIEMAT, Madrid,

Spain

${ }^{11}$ Laboratorio de Fisica de la Atmosfera, Universidad Mayor de San Andres, La Paz, Bolivia

${ }^{12}$ Institute for Nuclear Research and Nuclear Energy, Bulgarian Academy of Sciences, Sofia, Bulgaria

${ }^{13}$ Laboratory of Atmospheric Chemistry, Paul Scherrer Institute, Villigen PSI, Switzerland

$35{ }^{14}$ Saxon State Office for Environment, Agriculture and Geology (LfULG), Dresden, Germany

${ }^{15}$ German Environment Agency (UBA), Zugspitze, Germany

${ }^{16}$ Atmospheric Chemistry Research Group, Chemical Resource Beneficiation, North-West University, Potchefstroom, 2520, South Africa

${ }^{17}$ Department of Applied Physics, University of Granada, Granada, Spain

$40{ }^{18}$ Andalusian Institute for Earth System Research (IISTA-CEAMA), University of Granada, Autonomous Government of Andalusia, Granada, Spain 
${ }^{19}$ ANDRA DRD/GES Observatoire Pérenne de l'Environnement, 55290 Bure, France

${ }^{20}$ ERL, Institute of Nuclear and Radiological Science \& Technology, Energy \& Safety N.C.S.R. "Demokritos", Attiki, Greece

${ }^{21}$ Institut National de l'Environnement Industriel et des Risques (INERIS), Verneuil-en-Halatte, France

${ }^{22}$ German Weather Service, Meteorological Observatory Hohenpeissenberg, Hohenpeißenberg, Germany

$5 \quad{ }^{23}$ Department of Atmospheric Sciences, University of Utah, Salt Lake City, UT 84112, USA

${ }^{24}$ Environmental Chemical Processes Laboratory (ECPL), University of Crete, Heraklion, Crete, 71003, Greece

${ }^{25} \mathrm{TU}$ Wien - Institute of Chemical Technlogies and Analytics, Vienna, Austria

${ }^{26}$ CSIRO Oceans and Atmosphere, PMB1 Aspendale, VIC, Australia

${ }^{27}$ Global Atmosphere Watch Team, Innovative Meteorological Research Department, National Institute of Meteorological

10 Sciences, Seogwipo-si, Jeju-do, Korea

${ }^{28}$ School of Earth and Environmental Sciences, Seoul National University, Seoul, Korea

${ }^{29}$ Lund University, Department of Physics, Division of Nuclear Physics, Lund, Sweden

${ }^{30}$ Atmospheric composition research, Finnish Meteorological Institute, Helsinki, Finland

${ }^{31}$ Svalbard Integrated Arctic Earth Observing System, Longyearbyen, Svalbard, Norway

$15{ }^{32}$ Department of Atmospheric Sciences, National Central University, Taoyuan, Taiwan

${ }^{33}$ Center for Environmental Monitoring Technology, National Central University, Taoyuan, Taiwan

${ }^{34}$ Institute of Atmospheric Sciences and Climate, National Research Council of Italy, Bologna, Italy

${ }^{35}$ European Commission, Joint Research Centre (JRC), Ispra, Italy

${ }^{36}$ University of Puerto Rico, Rio Piedras Campus, San Juan, Puerto Rico

$20{ }^{37}$ Observatoire des Sciences de l'Univers de La Réunion (OSUR), UMS3365, Saint-Denis de la Réunion, France

${ }^{38}$ Institute of Environmental Research \& Sustainable Development, National Observatory of Athens,

Palea Penteli, 15236, Greece

${ }^{39}$ Department of Aerosol Chemistry and Physics, Institute of Chemical Process Fundamentals, CAS, Prague, Czech Republic

${ }^{40}$ Laboratoire des Sciences du Climat et de l'Environnement, LSCE/IPSL, UMR 8212 CEA-CNRS-UVSQ, Université Paris-

25 Saclay, Gif-sur-Yvette, France

${ }^{41}$ Laboratoire d'Aérologie, CNRS-Université de Toulouse, CNRS, UPS, Toulouse, France

${ }^{42}$ Environment and Climate Change Canada, Toronto, ON, Canada

${ }^{43}$ ZAMG - Sonnblick Observatory, 5020 Salzburg, Austria

${ }^{44}$ Department of Physics and Astronomy, Appalachian State University, Boone, NC, USA

$30{ }^{45}$ Atmospheric Sounding Station, El Arenosillo, Atmospheric Research and Instrumentation Branch, INTA, 21130, Mazagón, Huelva, Spain

${ }^{46}$ State Key Laboratory of Severe Weather \& Key Laboratory of Atmospheric Chemistry of CMA, Chinese Academy of Meteorological Sciences, Beijing 100081, China

${ }^{47}$ Laboratoire de l'Atmosphère et des Cyclones (LACy), UMR8105, Université de la Réunion - CNRS - Météo-France, Saint-

35 Denis de La Réunion, France

484S Company, 63000 Clermont Ferrand, France

${ }^{49}$ Alfred-Wegener-Institut, Helmholtz-Zentrum für Polar- und Meeresforschung, 27570 Bremerhaven, Germany

${ }^{50}$ Univ. Grenoble-Alpes, CNRS, IRD, Grenoble-INP, IGE, 38000 Grenoble, France

*now at University of Basel, Department of Environmental Sciences, Basel, Switzerland

Correspondence to: c.rose@opgc.fr

\section{Effect of cut-off diameters different from $10 \mathrm{~nm}$ on the calculation of $\mathbf{N}_{\text {tot }}$ - Comparison of $\mathbf{N}_{\text {tot }}$ derived from collocated MPSS and CPC measurements}

The influence on $\mathrm{N}_{\text {tot }}$ of cut-off diameters different from $10 \mathrm{~nm}$ (either lower or higher) was evaluated based on measurements

performed with MPSS detecting particles over broad enough size ranges and sufficient annual data availability (> 60\%, See

Sect. 4.1). The effect of including sub-10 nm particles in $\mathrm{N}_{\text {tot }}$ was investigated first: the ratio of the particle concentration in 
the range 3-10 nm ( $\left.\mathrm{N}_{3-10}\right)$ over $\mathrm{N}_{\text {tot }}$ was more specifically calculated using data collected at VAR and SMR, and the same was repeated for the size range 5-10 $\mathrm{nm}\left(\mathrm{N}_{5-10}\right)$ using data collected at MEL, LEI, LEI-M and DRN. Because the objective of this analysis was not to deeply investigate the seasonal variations of the contribution of sub-10 nm particles to $\mathrm{N}_{\text {tot }}$, the analysis was performed at the annual scale only, and the variability of this contribution, likely related to the variability of the particle

5 sources, was evaluated based on the percentiles of the calculated ratios. As illustrated in Fig. S1, the ratio of $\mathrm{N}_{3-10}$ over $\mathrm{N}_{\text {tot }}$ calculated for the two Finnish sites is of the order of $2 \%$ on average; it is mostly below $7 \%$ ( $75^{\text {th }}$ percentile) and rarely exceeds $17 \%$ ( $90^{\text {th }}$ perc.). In contrast, the ratio of $\mathrm{N}_{5-10}$ over $\mathrm{N}_{\text {tot }}$ derived for the 4 German sites is slightly higher, $15 \%$ on average, and can be as high as $45 \%$ ( $90^{\text {th }}$ perc.). A detailed analysis of these observations with respect to the station types is beyond the scope of this study; it is however likely that these last results are related to the contrasting environments of the sites, with

10 higher concentrations of sub-10 nm particles (with respect to $\mathrm{N}_{\text {tot }}$ ) observed at urban sites in all seasons in connection with traffic. Because none of the stations equipped with a CPC detecting particles down $2.5 \mathrm{~nm}$ (ARN, ETL and GSN) are located in an urban area, we believe that the measurements performed at these sites will not lead to a strong overestimation of $\mathrm{N}_{\text {tot. }}$.

Using the same approach, the effect caused by a lack of measurement in the lowest sizes of the reference range $(10-500 \mathrm{~nm})$ was then investigated. The ratios of the particle concentration in the range 10-12 $\mathrm{nm}\left(\mathrm{N}_{10-12}\right)$ and 10-20 $\mathrm{nm}\left(\mathrm{N}_{10-20}\right)$ over $\mathrm{N}_{\text {tot }}$

15 were calculated based on data collected at a relatively large subset of stations (27) representative of various conditions (ANB, BIR, CHC, DEM, DRN, DRW, DTC, FKL, HPB, SMR, IPR, KOS, KPS, LEI, LEI-E, LEI-M, MEL, NGL, OPE, PAL, PRG, SSL, TRL, VAR, WAL, ZEP and ZSF). The ratio of $\mathrm{N}_{10-12}$ over $\mathrm{N}_{\text {tot }}$ is on average of the order of $2 \%$, mostly below $9 \%$ ( $90^{\text {th }}$ perc.), suggesting that such a small cut-point difference is not a major issue for $\mathrm{N}_{\text {tot }}$ (Fig. S1). In contrast, the lack of measurement in the sub- $20 \mathrm{~nm}$ range might have a stronger effect on $\mathrm{N}_{\text {tot }}$, as the contribution of these particles to $\mathrm{N}_{\text {tot }}$ is on

20 average of the order of $13 \%$, and can be up to 38\%. This last observation should be kept in mind, specifically when considering the data from MAD and JFJ, where the lower cut-points are $\sim 15$ and $\sim 17 \mathrm{~nm}$, respectively (Table 1).

As a last sensitivity test, the particle concentration in the range $500-800 \mathrm{~nm}\left(\mathrm{~N}_{500-800}\right)$ was compared to $\mathrm{N}_{\text {tot }}$ using measurements performed at 22 sites (ANB, BIR, DRN, DRW, DTC, FKL, GIF, HPB, SMR, IPR, KOS, LEI, LEI-E, LEI-M, MEL, MSY, NGL, SSL, TRL, WAL, WGG and ZEP). As shown in Fig. S1, $\mathrm{N}_{500-800}$ is on average much lower compared to $\mathrm{N}_{\text {tot }}$ (ratio of 25 the order of $0.1 \%$ on average). This clearly indicates that larger particles contribute little to the particle number concentration in all environments, and suggests, in turn, that the higher cut-off of $500 \mathrm{~nm}$ used for the derivation of $\mathrm{N}_{\text {tot }}$ from MPSS data has no strong effect on the results. 


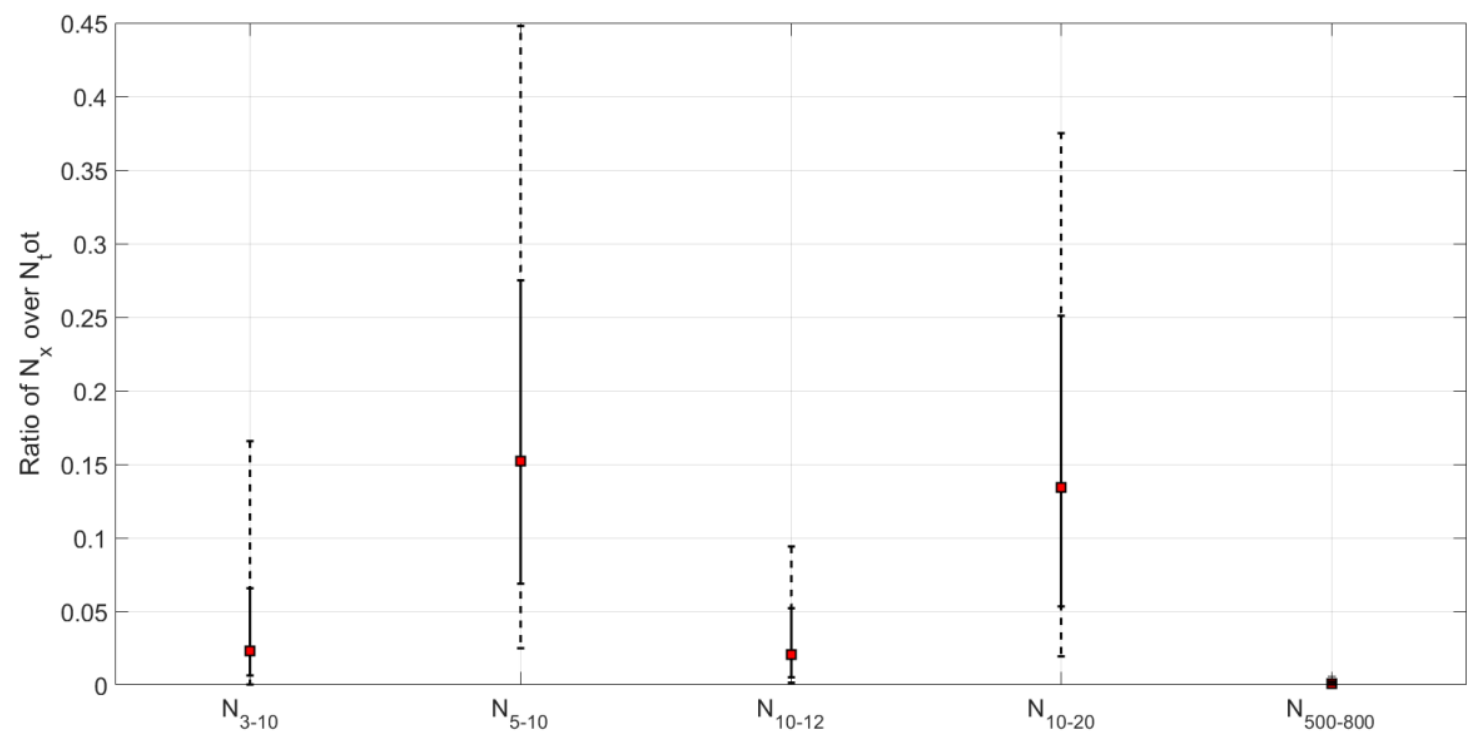

Fig. S1 Ratios of the particle number concentration in different size ranges $\left(\mathrm{N}_{\mathrm{x}}\right)$ over $\mathrm{N}_{\text {tot }} . \mathrm{N}_{\mathrm{x}}$ denotes $\mathrm{N}_{3-10}, \mathrm{~N}_{5-10}, \mathrm{~N}_{10-12}, \mathrm{~N}_{10-}$ 20 and $\mathrm{N}_{500-800}$, which correspond to the concentrations in the size ranges 3-10, 5-10, 10-12, 10-20 and 500-800 nm, respectively. The markers represent the median of the ratios, the lower and upper limits of the solid error bars indicate the $1^{\text {st }}$ and $3^{\text {rd }}$ quartile, 5 respectively, and the lower and upper limits of the dashed error bars indicate the $10^{\text {th }}$ and $90^{\text {th }}$ percentiles of the ratios, respectively. 

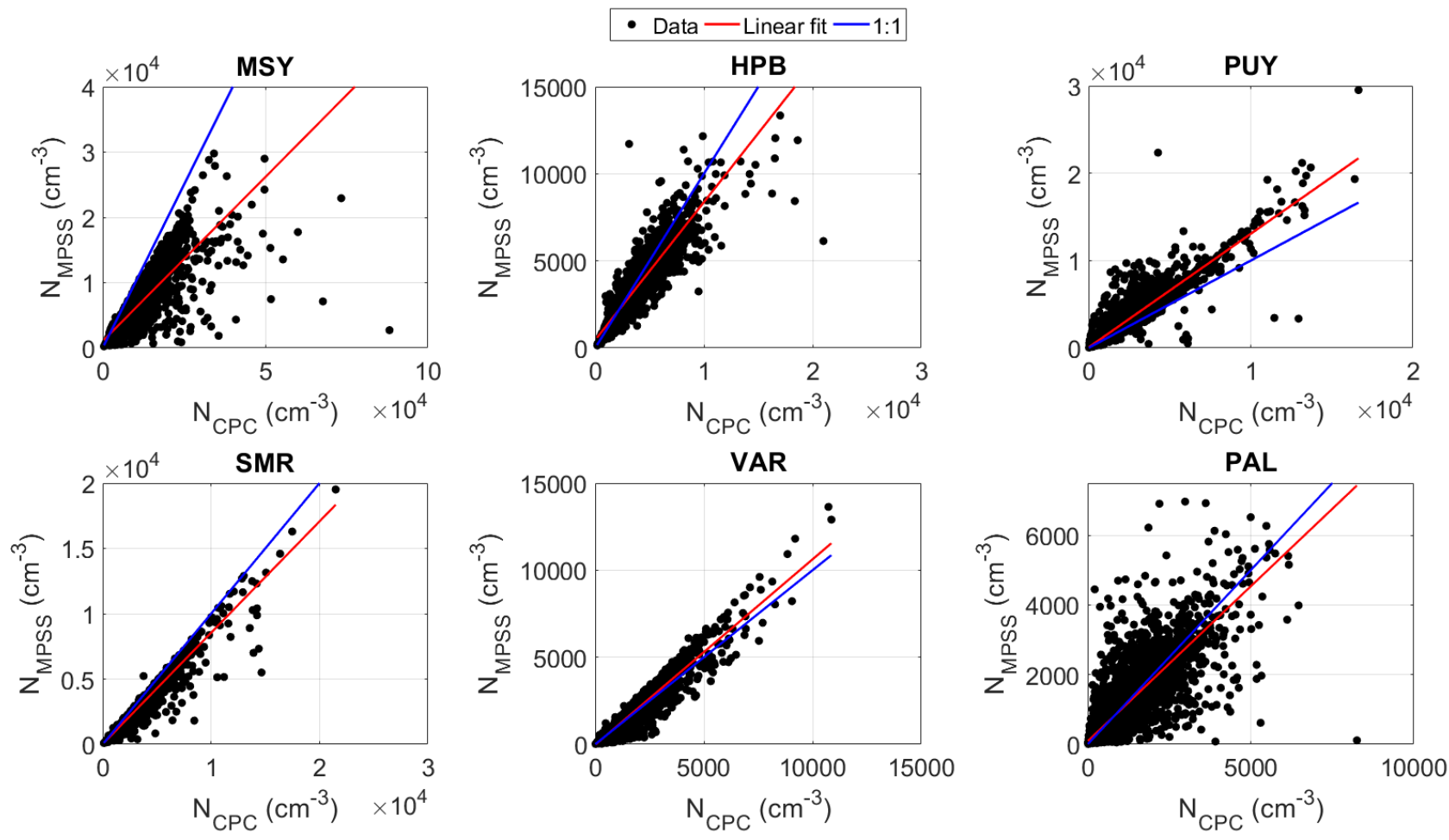

10 Fig. S2 Comparison of $\mathrm{N}_{\text {tot }}$ derived from collocated CPC $\left(\mathrm{N}_{\mathrm{CPC}}\right)$ and MPSS $\left(\mathrm{N}_{\mathrm{MPSS}}\right)$ measurements.

Table S1 Comparison of $\mathrm{N}_{\text {tot }}$ derived from collocated CPC and MPSS measurements. For each site, the coefficient of determination obtained between the values of $\mathrm{N}_{\text {tot }}$ derived from each instrument as well as the equation of the linear fit shown in Fig. S2 are reported.

\begin{tabular}{l|cc}
\hline Station & $\mathrm{R}^{2}$ & Fit equation \\
\hline MSY & 0.76 & $\mathrm{~N}_{\mathrm{MPSS}}=0.50 \times \mathrm{N}_{\mathrm{CPC}}+1034$ \\
HPB & 0.84 & $\mathrm{~N}_{\mathrm{MPSS}}=0.79 \times \mathrm{N}_{\mathrm{CPC}}+453$ \\
PUY & 0.87 & $\mathrm{~N}_{\mathrm{MPSS}}=1.30 \times \mathrm{N}_{\mathrm{CPC}}+61$ \\
SMR & 0.96 & $\mathrm{~N}_{\mathrm{MPSS}}=0.85 \times \mathrm{N}_{\mathrm{CPC}}+15$ \\
VAR & 0.94 & $\mathrm{~N}_{\mathrm{MPSS}}=1.07 \times \mathrm{N}_{\mathrm{CPC}}-30$ \\
PAL & 0.74 & $\mathrm{~N}_{\mathrm{MPSS}}=0.89 \times \mathrm{N}_{\mathrm{CPC}}+89$ \\
\hline
\end{tabular}




\section{Coverage criteria for the calculation of $\mathbf{N}_{\text {tot }}$ annual and seasonal statistics}

Similar to the analysis reported in Sect. 4.1 at the annual scale, the effect of long gaps in the data was investigated at the seasonal scale, for which the exclusion of non-contiguous weeks was also tested (this was not tested at the annual scale due to the high number of possible combinations). As shown in Fig. S3, the most pronounced variability is, again, observed for the

5 polar sites, specifically those in the Southern Hemisphere (TRL and NMY) during MAM, consistent with a strong variation of $\mathrm{N}_{\text {tot }}$ during this time of the year (see Fig. 7). Besides these two sites, noticeable variability is also seen for ETL in DJF, and is also likely explained by the variability of $\mathrm{N}_{\text {tot }}$ at the site during this period. Otherwise, the effect of reduced data availability on the seasonal statistics seems to be limited, at least for datasets with up to 6 missing weeks. The median values derived from the original and from the reduced datasets are mostly within a factor of 1.5 and they tend to be homogeneously distributed

10 around 1. Regarding the configuration of the missing period (contiguous vs non-contiguous weeks), there is no clear effect up to 3 weeks missing, and for longer periods, contrasting results are obtained depending on the season. Indeed, when simulating the absence of 4-6 weeks, the exclusion of non-contiguous weeks leads to broader dispersion of the medians in DJF, but to smaller dispersion during MAM (particularly visible for TRL and NMY), and there is no difference in JJA and SON.

The effect of excluding individual hourly averages was also evaluated. Figure S4 shows the results obtained when the data

15 availability was artificially decreased to $75,60,50$ and $25 \%$. For each target data availability, individual data points to exclude were randomly selected, and the test was performed 25 times to get more insight into the variability of the results. In a similar way as previously done for the longer gaps, the medians and percentiles derived from the shorter datasets were compared to those of the original dataset. Changes in the statistics are logically more obvious when decreasing the amount of data but remain relatively limited (at both scales, annual and seasonal), with all ratios between 0.8 and 1.3 , homogeneously distributed around 1. It appears that the impact of sporadic/short gaps on the statistics is less pronounced compared to the exclusion of longer «blocks» of data resulting in similar data availability (e.g. 6 weeks vs 50\% at the seasonal scale and 24 weeks vs 50\% at the annual scale). The effect is nonetheless, on average, more pronounced at the seasonal scale, and particularly for MAM, and is again the strongest for the polar sites, which experience the most amplitude in the seasonal cycle. 

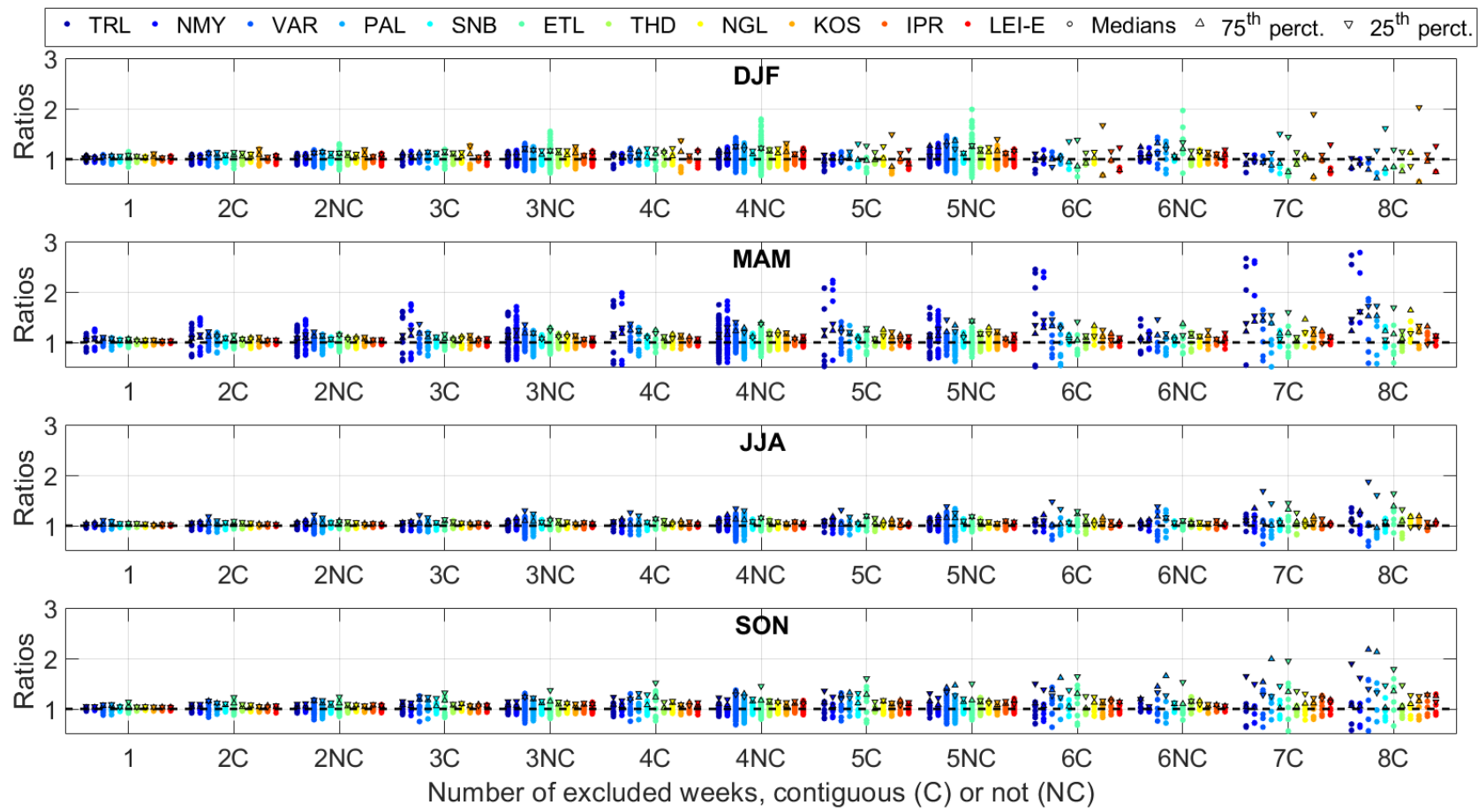

Fig. S3 Variability of $\mathrm{N}_{\text {tot }}$ seasonal statistics in reduced datasets. For each investigated gap length and configuration (i.e. 1 to 208 weeks, contiguous or not), all possible combinations of weeks to exclude were tested, and in each case the ratio between the newly derived median of $\mathrm{N}_{\text {tot }}$ and that derived from the original dataset was calculated (circles). The upward and downward triangles provide insight into the range of variability. The upfacing triangles represent the ratio between the maximum value of the $75^{\text {th }}$ percentile of $\mathrm{N}_{\text {tot }}$ obtained from the reduced datasets and the $75^{\text {th }}$ percentile calculated from the original time series. The downfacing triangles represent the $25^{\text {th }}$ percentile from the original dataset divided by the minimum of the $25^{\text {th }}$ percentile. 

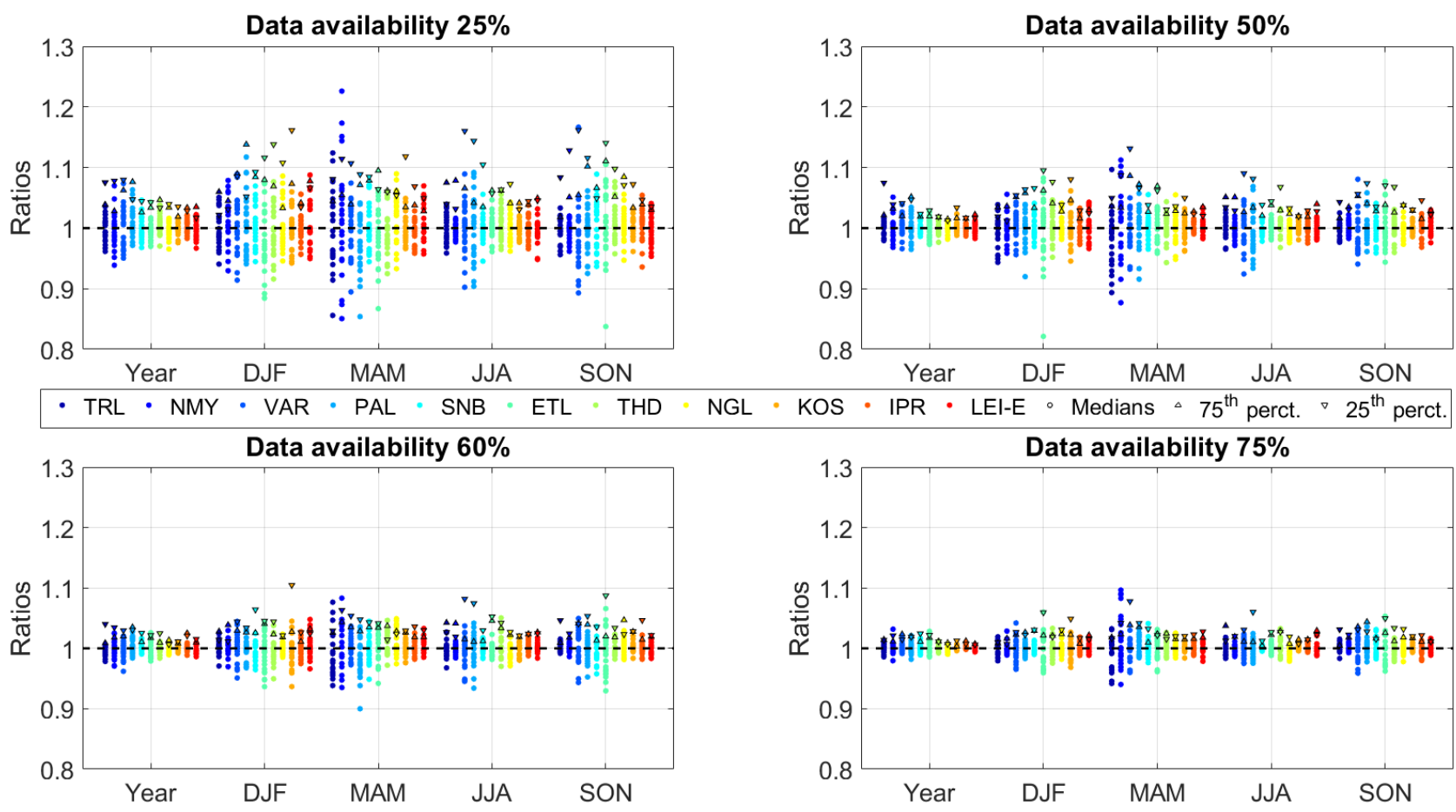

Fig. S4 Variability of $\mathrm{N}_{\text {tot }}$ annual and seasonal statistics in reduced datasets. For each period (year or season), individual hourly averages were randomly excluded to reach four target data availabilities to be investigated $(25 \%, 50 \%, 60 \%$ and $75 \%)$. In each case, the test was repeated 25 times, and the ratio between the newly derived median of $\mathrm{N}_{\text {tot }}$ and that derived from the original dataset was calculated (circles). The upward and downward triangles provide insight into the range of variability. The upfacing

5 triangles represent the ratio between the maximum value of the $75^{\text {th }}$ percentile of $\mathrm{N}_{\text {tot }}$ obtained from the reduced datasets and the $75^{\text {th }}$ percentile calculated from the original time series. The downfacing triangles represent the $25^{\text {th }}$ percentile from the original dataset divided by the minimum of the $25^{\text {th }}$ percentile. 


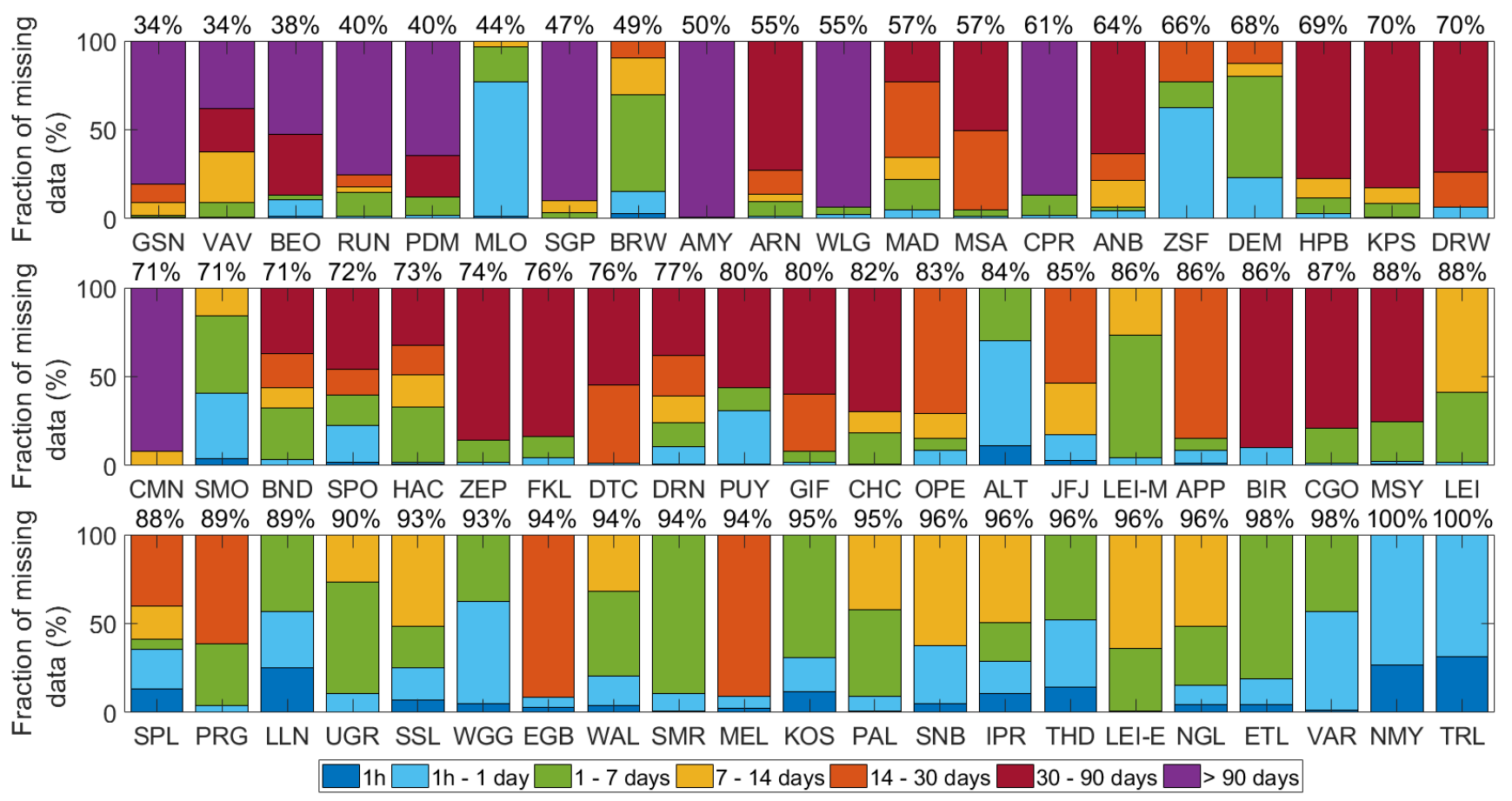

Fig. S5 Statistics regarding the length of the interruption periods observed in the different datasets at the annual scale. The 20 sites are sorted by ascending order of their annual data availability, which is reported at the top of each panel. 


\section{Seasonal variation of the total particle number concentration and size distribution}
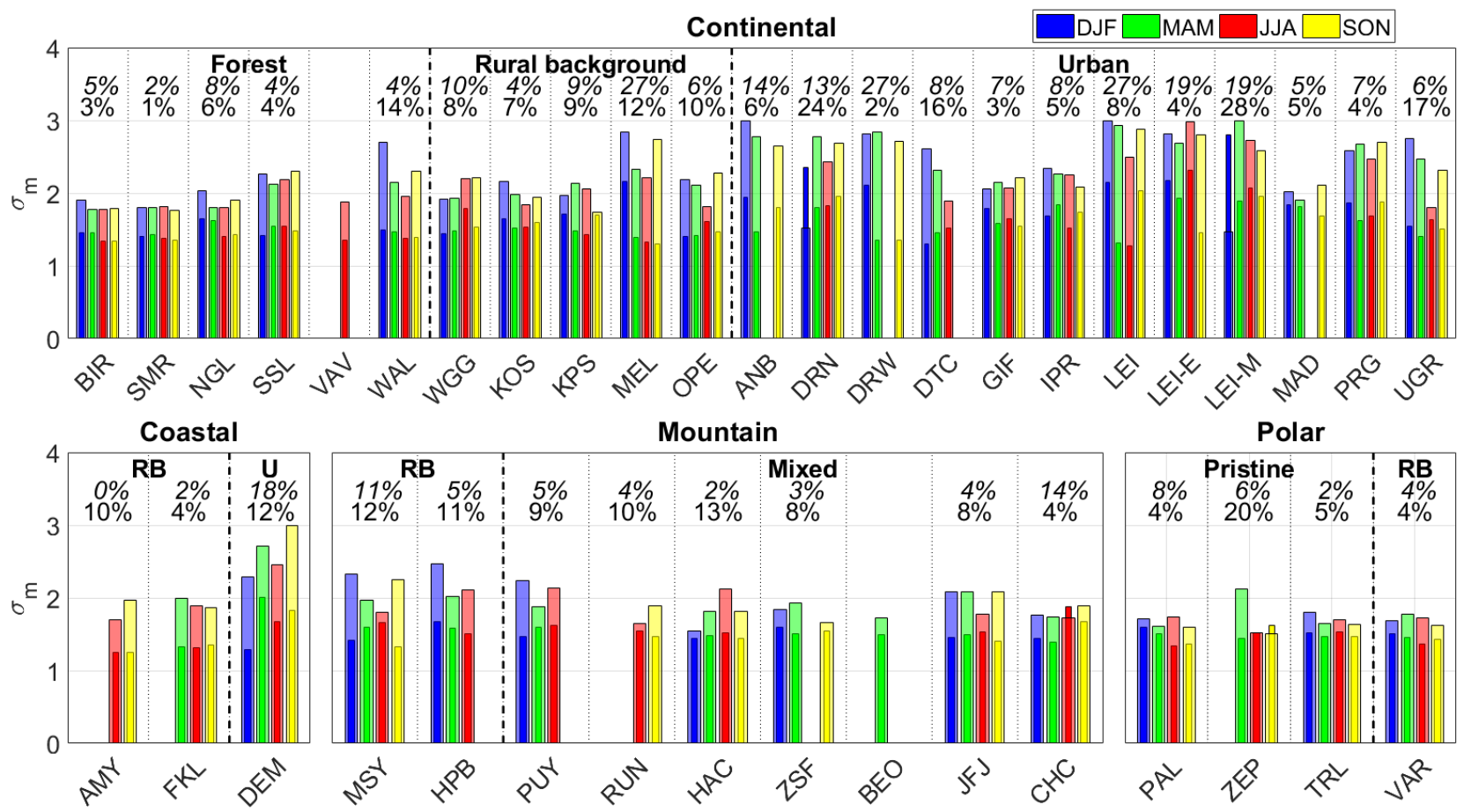

20 Fig. S6 Geometric standard deviation of the modes. For each site and season, the thicker bar represents the standard deviation of the Aitken mode $\left(\sigma_{m, 1}\right)$ and the thinner one that of the accumulation mode $\left(\sigma_{m, 2}\right)$. In addition, the values at the top of each panel indicate the site-specific variability of geometric standard deviation, with the italicized text corresponding to $\sigma_{m, 2}$. The meaning of the abbreviations used for the footprint is the following: RB for rural background and $U$ for urban. Details regarding the calculation of the site-specific variability of the modes characteristics are available in Sect. 5.1. 
Table S2 Overview of $\mathrm{N}_{\text {tot }}$ measurements. For each site, the annual statistics (i.e. median, 10th and 90th percentiles) of $\mathrm{N}_{\text {tot }}$ are only reported when corresponding data availability is above $60 \%$, and seasonal statistics are reported when corresponding data availability is above $50 \%$.

\begin{tabular}{|c|c|c|c|c|c|c|c|c|c|c|c|c|c|c|c|}
\hline \multirow{2}{*}{ Station } & \multicolumn{3}{|c|}{ Year } & \multicolumn{3}{|c|}{ DJF } & \multicolumn{3}{|c|}{ MAM } & \multicolumn{3}{|c|}{ JJA } & \multicolumn{3}{|c|}{ SON } \\
\hline & Med. & $10^{\text {th }}$ & $90^{\text {th }}$ & Med. & $10^{\text {th }}$ & $90^{\text {th }}$ & Med. & $10^{\text {th }}$ & $90^{\text {th }}$ & Med. & $10^{\text {th }}$ & $90^{\text {th }}$ & Med. & $10^{\text {th }}$ & $90^{\text {th }}$ \\
\hline \multicolumn{16}{|c|}{ WMO I, Africa } \\
\hline RUN & - & - & - & - & - & - & - & - & - & 605 & 196 & 3924 & 656 & 240 & 2416 \\
\hline WGG & 3798 & 1369 & 14024 & 3513 & 1286 & 12806 & 3916 & 1401 & 12627 & 3755 & 1506 & 14292 & 4004 & 1286 & 16185 \\
\hline \multicolumn{16}{|c|}{ WMO II, Asia } \\
\hline AMY & - & - & - & - & - & - & - & - & - & 3175 & 1630 & 6280 & 4247 & 2257 & 7659 \\
\hline GSN & - & - & - & - & - & - & 2761 & 1439 & 5049 & - & - & - & - & - & - \\
\hline LLN & 1106 & 388 & 2779 & 810 & 307 & 2034 & 1466 & 554 & 2661 & 1080 & 380 & 3214 & 1121 & 395 & 3238 \\
\hline WLG & - & - & - & 2332 & 953 & 5881 & 2021 & 735 & 5712 & 1047 & 414 & 2646 & - & - & - \\
\hline \multicolumn{16}{|c|}{ WMO III, South America } \\
\hline $\mathrm{CHC}$ & 2644 & 578 & 15307 & 1246 & 410 & 5588 & 2252 & 526 & 13827 & 5483 & 1303 & 27475 & 2557 & 748 & 12051 \\
\hline \multicolumn{16}{|c|}{ WMO IV, North America, Central America and the Caribbean } \\
\hline ALT & 153 & 53 & 426 & 101 & 53 & 235 & 201 & 77 & 354 & 256 & 66 & 686 & 88 & 37 & 379 \\
\hline APP & 2555 & 1146 & 5309 & 2684 & 1014 & 5613 & 2815 & 1146 & 6522 & 2339 & 1304 & 3984 & 2593 & 1070 & 5064 \\
\hline BND & 2125 & 668 & 5920 & 1454 & 395 & 4720 & 3313 & 1217 & 7340 & 1797 & 681 & 4914 & 2222 & 660 & 5848 \\
\hline BRW & 128 & 40 & 599 & 148 & 48 & 354 & 132 & 54 & 417 & 140 & 36 & 1038 & 107 & 26 & 623 \\
\hline CPR & 1235 & 686 & 3010 & - & - & - & - & - & - & 1153 & 629 & 2688 & 1372 & 721 & 3125 \\
\hline EGB & 2594 & 648 & 7295 & 2541 & 683 & 7126 & 1329 & 281 & 5071 & 2701 & 1120 & 6464 & 3893 & 913 & 9022 \\
\hline ETL & 1116 & 189 & 3328 & 731 & 135 & 2742 & 724 & 192 & 3592 & 1508 & 707 & 3723 & 1159 & 162 & 3533 \\
\hline SGP & - & - & - & 3496 & 938 & 6789 & 3422 & 1324 & 7874 & - & - & - & - & - & - \\
\hline SPL & 2159 & 803 & 6709 & 1657 & 624 & 5005 & 2161 & 672 & 7562 & 2773 & 1410 & 8373 & 2062 & 905 & 6262 \\
\hline THD & 1038 & 404 & 2519 & 1100 & 394 & 2817 & 1006 & 395 & 2552 & 932 & 399 & 2252 & 1162 & 436 & 2520 \\
\hline \multicolumn{16}{|c|}{ WMO V, South-West Pacific } \\
\hline $\mathrm{CGO}$ & 559 & 136 & 2797 & 733 & 292 & 1803 & 722 & 166 & 3213 & 282 & 93 & 2847 & 583 & 170 & 2797 \\
\hline MLO & 409 & 280 & 696 & 414 & 280 & 749 & 376 & 275 & 642 & 438 & 304 & 694 & 408 & 254 & 708 \\
\hline SMO & 284 & 175 & 420 & 304 & 200 & 604 & 215 & 142 & 344 & 275 & 177 & 388 & 330 & 221 & 431 \\
\hline \multicolumn{16}{|c|}{ WMO VI, Europe } \\
\hline ANB & 4562 & 1783 & 14145 & 4987 & 1622 & 17827 & 4621 & 2151 & 12785 & - & - & - & 4021 & 1646 & 10583 \\
\hline ARN & - & - & - & - & - & - & 4996 & 1668 & 11950 & - & - & - & 6332 & 3575 & 14475 \\
\hline BIR & 1009 & 232 & 2878 & 553 & 149 & 1555 & 998 & 276 & 2648 & 1889 & 867 & 4158 & 963 & 212 & 2551 \\
\hline BEO & - & - & - & - & - & - & 670 & 215 & 1864 & - & - & - & - & - & - \\
\hline $\mathrm{CMN}$ & 961 & 261 & 2212 & 314 & 102 & 931 & 1089 & 434 & 2509 & 1216 & 695 & 2352 & - & - & - \\
\hline DEM & 6198 & 2711 & 15075 & 5666 & 1898 & 15269 & 8887 & 4138 & 18423 & 5208 & 3071 & 12089 & 5754 & 2500 & 13515 \\
\hline
\end{tabular}




\begin{tabular}{|c|c|c|c|c|c|c|c|c|c|c|c|c|c|c|c|}
\hline DRN & 7962 & 4037 & 15213 & 7558 & 3471 & 15836 & 7414 & 4008 & 13749 & 8964 & 5069 & 15856 & 8272 & 4025 & 15455 \\
\hline DRW & 4579 & 1993 & 10148 & 4414 & 1596 & 9953 & 4411 & 2335 & 10394 & - & - & - & 4097 & 1979 & 9051 \\
\hline DTC & 3692 & 1513 & 10893 & 2921 & 1127 & 7927 & 3813 & 1715 & 11181 & 4381 & 2059 & 17022 & - & - & - \\
\hline FKL & 2731 & 1427 & 4969 & - & - & - & 2716 & 1662 & 5237 & 3353 & 2095 & 5116 & 2320 & 1400 & 4741 \\
\hline GIF & 3331 & 1218 & 8253 & 2658 & 795 & 7512 & 3530 & 1599 & 8221 & 3722 & 1422 & 9462 & 3071 & 1069 & 7565 \\
\hline HAC & 1004 & 240 & 2909 & 405 & 150 & 1517 & 1193 & 399 & 3610 & 1862 & 899 & 3389 & 637 & 233 & 2047 \\
\hline HРB & 2737 & 1192 & 4836 & 2055 & 927 & 3737 & 2872 & 1233 & 5011 & 3066 & 1458 & 5370 & - & - & - \\
\hline IPR & 6810 & 3057 & 14382 & 10071 & 3577 & 18774 & 5849 & 3171 & 11066 & 5757 & 2868 & 9581 & 7528 & 2845 & 13641 \\
\hline JFJ & 193 & 56 & 590 & 106 & 32 & 338 & 191 & 72 & 602 & 378 & 162 & 786 & 158 & 62 & 392 \\
\hline KOS & 2690 & 1111 & 5159 & 2162 & 617 & 4849 & 2807 & 1323 & 5948 & 3371 & 2067 & 6131 & 2192 & 1117 & 3916 \\
\hline KPS & 4798 & 2747 & 9422 & 4426 & 2502 & 8090 & 4983 & 2661 & 11650 & 5003 & 3241 & 9505 & 4768 & 2779 & 8269 \\
\hline LEI & 5088 & 2486 & 10182 & 4889 & 2120 & 9525 & 5114 & 2426 & 10303 & 5594 & 3080 & 12012 & 4697 & 2501 & 9346 \\
\hline LEI-E & 8573 & 3859 & 18002 & 7233 & 2903 & 16737 & 9467 & 4862 & 17970 & 10375 & 5511 & 21266 & 6875 & 3289 & 14810 \\
\hline LEI-M & 10130 & 4634 & 21699 & 9512 & 3759 & 22274 & 10556 & 5087 & 21435 & 8983 & 4643 & 19959 & 11056 & 5146 & 22994 \\
\hline MAD & - & - & - & 10107 & 2127 & 24045 & 7586 & 2865 & 16431 & - & - & - & 8534 & 3350 & 19913 \\
\hline MEL & 4434 & 2154 & 8361 & 3769 & 1727 & 6936 & 4602 & 2154 & 9538 & 5278 & 2871 & 11767 & 4154 & 2219 & 6643 \\
\hline MSA & - & - & - & - & - & - & 4494 & 1840 & 13510 & 4661 & 1631 & 13340 & 2853 & 861 & 10283 \\
\hline MSY & 3007 & 1158 & 8261 & 1847 & 805 & 4712 & 3252 & 1407 & 8232 & 4247 & 1806 & 11519 & 3049 & 1384 & 7465 \\
\hline NGL & 2579 & 1025 & 5507 & 1601 & 637 & 3145 & 2246 & 914 & 5247 & 3718 & 2055 & 7019 & 2892 & 1453 & 5266 \\
\hline OPE & 2412 & 995 & 4775 & 2018 & 760 & 4826 & 3192 & 1660 & 5482 & 2824 & 1344 & 5330 & 1926 & 891 & 3367 \\
\hline PAL & 356 & 68 & 1839 & 146 & 51 & 526 & 627 & 128 & 2296 & 1050 & 208 & 2300 & 222 & 47 & 1183 \\
\hline PDM & - & - & - & 330 & 62 & 2131 & - & - & - & - & - & - & 788 & 223 & 3403 \\
\hline PRG & 6077 & 2528 & 13129 & 5719 & 2022 & 12304 & 5132 & 2391 & 11641 & 7810 & 3602 & 15444 & 6352 & 2906 & 13820 \\
\hline PUY & 1968 & 457 & 5080 & 785 & 300 & 2490 & 2177 & 538 & 5119 & 2948 & 978 & 6566 & - & - & - \\
\hline SMR & 1259 & 430 & 3074 & 812 & 330 & 2006 & 1526 & 620 & 3865 & 2011 & 892 & 3735 & 928 & 336 & 2136 \\
\hline SNB & 1027 & 291 & 2562 & 636 & 189 & 1529 & 1223 & 417 & 3096 & 1737 & 720 & 2993 & 811 & 270 & 2093 \\
\hline SSL & 1873 & 491 & 4448 & 832 & 318 & 2009 & 2878 & 935 & 5671 & 2794 & 1281 & 5182 & 1599 & 518 & 3436 \\
\hline UGR & 7477 & 3234 & 17694 & 10910 & 4512 & 27024 & 7601 & 3672 & 15668 & 5719 & 2652 & 11533 & 7588 & 3180 & 17262 \\
\hline VAR & 391 & 77 & 2027 & 178 & 48 & 554 & 624 & 142 & 2164 & 1355 & 273 & 2874 & 240 & 53 & 995 \\
\hline VAV & - & - & - & - & - & - & - & - & - & 2148 & 1281 & 4936 & - & - & - \\
\hline WAL & 3350 & 1524 & 6309 & 2519 & 1103 & 5380 & 3701 & 1508 & 7501 & 4162 & 2193 & 7407 & 3110 & 1760 & 5301 \\
\hline ZEP & 153 & 25 & 573 & - & - & - & 227 & 105 & 468 & 276 & 79 & 981 & 62 & 19 & 342 \\
\hline ZSF & 827 & 228 & 2550 & 520 & 162 & 1496 & 1298 & 302 & 3425 & - & - & - & 650 & 241 & 1661 \\
\hline \multicolumn{16}{|c|}{ WMO VII, Antarctica } \\
\hline NMY & 252 & 49 & 783 & 496 & 275 & 1397 & 186 & 51 & 701 & 62 & 36 & 155 & 293 & 116 & 530 \\
\hline SPO & 217 & 33 & 461 & 316 & 225 & 649 & 240 & 134 & 590 & 38 & 25 & 71 & 244 & 83 & 473 \\
\hline TRL & 306 & 45 & 761 & 537 & 319 & 1385 & 155 & 48 & 528 & 55 & 33 & 167 & 375 & 153 & 603 \\
\hline
\end{tabular}




\section{Focus on $\mathrm{CCN}$-sized particles}
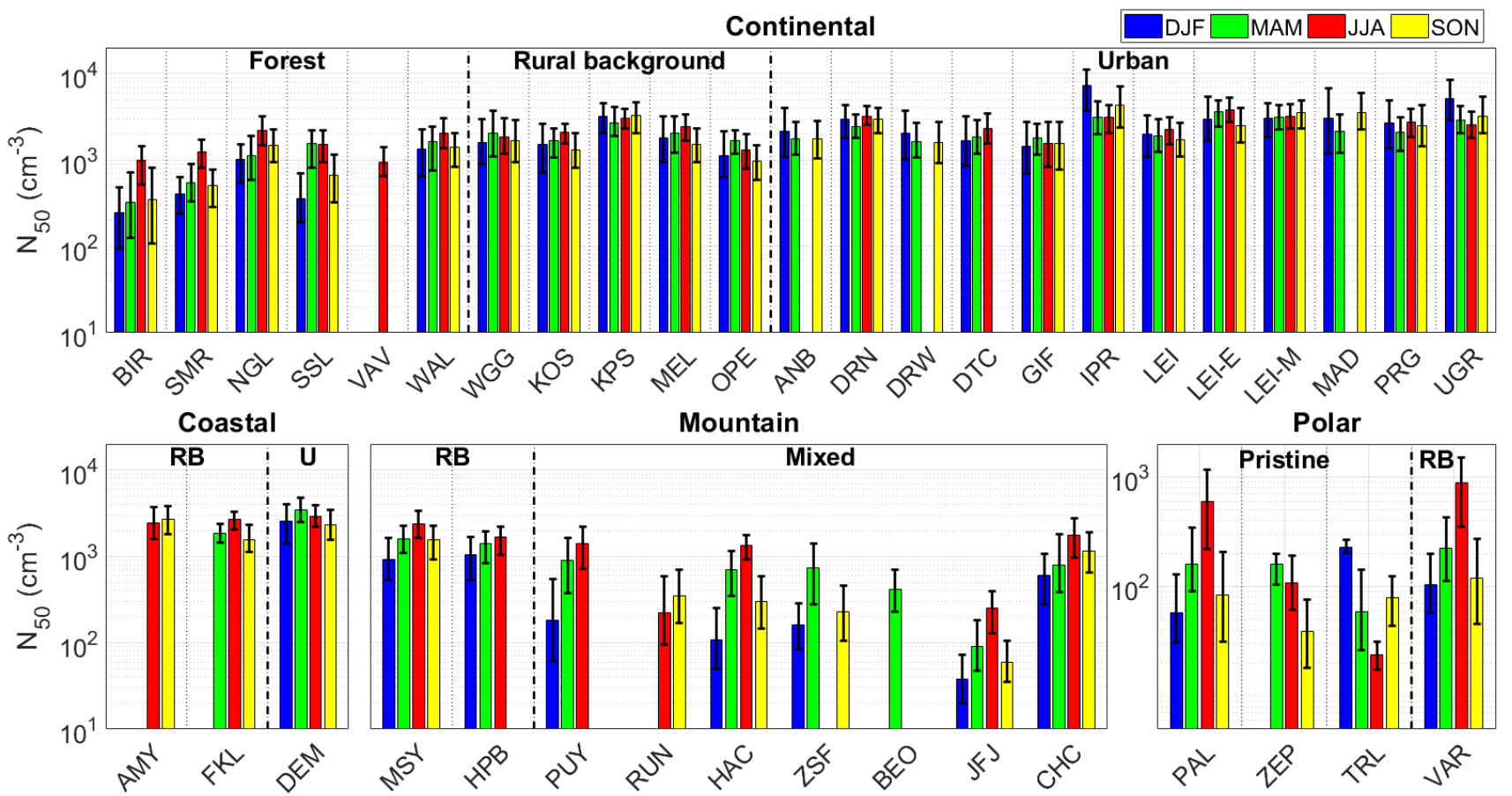

Fig. S7 Seasonal statistics of $\mathrm{N}_{50}$, the particle number concentration in the range 50-500 nm, used as an additional proxy for potential CCN population. The bars represent the median of $\mathrm{N}_{50}$, and the lower and upper end of the error bars represent the $1^{\text {st }}$ and $3^{\text {rd }}$ quartile of the data, respectively. Stations are sorted based on the classification reported in Table 1 . The meaning of the abbreviations used for the footprint is the following: RB for rural background and $\mathrm{U}$ for urban. 

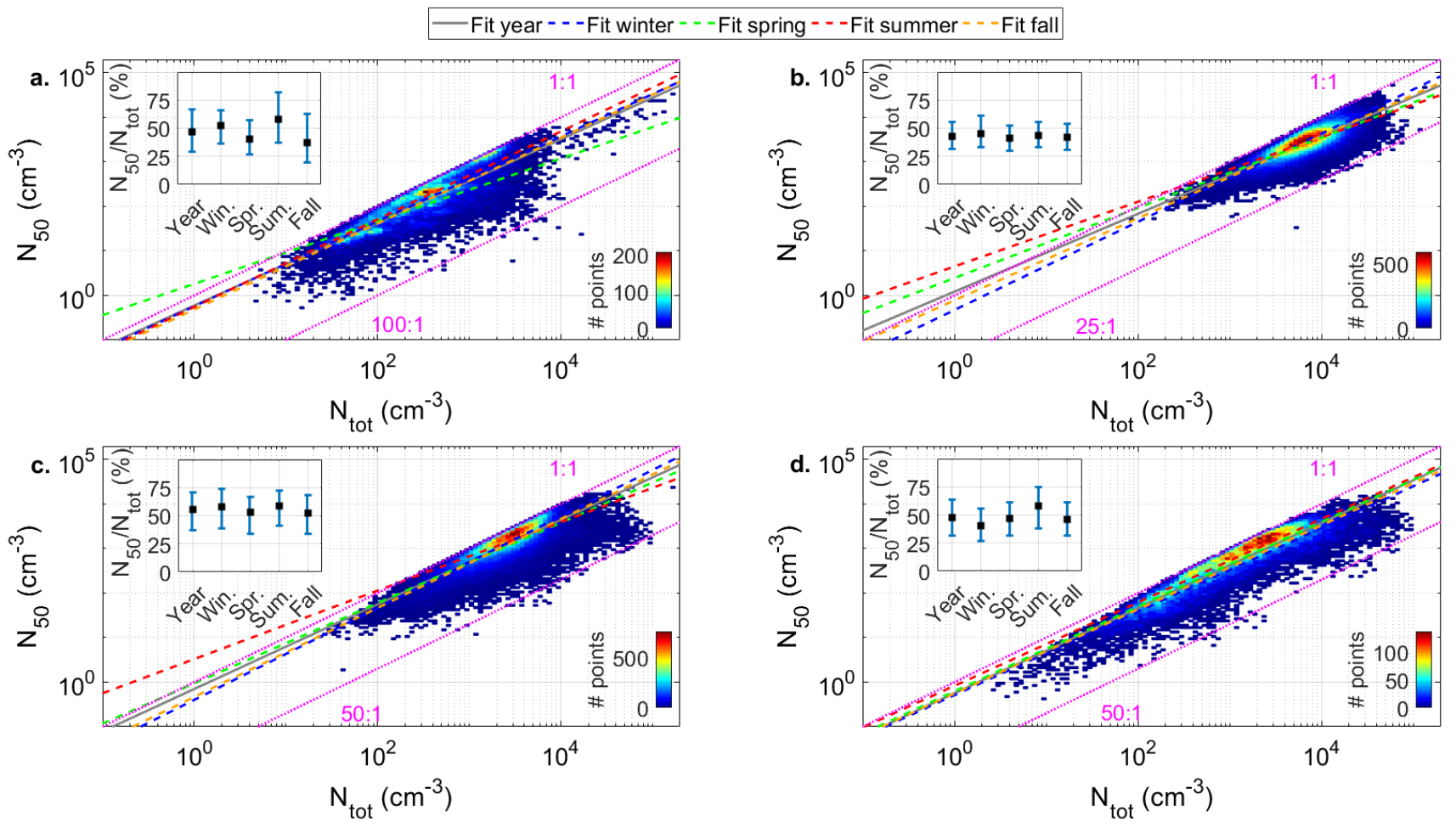

Fig. S8 Scatter plots of $\mathrm{N}_{50}$ as a function of $\mathrm{N}_{\text {tot }}$ (hourly averages) for the different station types: a. polar sites, b. urban sites, c. other lowland sites and d. mountain sites. The color of each pixel indicates the number of data points (hourly averages) falling into its area (all pixels have equal area on a log-log scale). The linear fit performed on the logarithm of the data, separately for each period (year and seasons), is also presented. The statistics of the ratio between $\mathrm{N}_{50}$ and $\mathrm{N}_{\text {tot }}$ calculated for each or these periods are in addition shown for each station type in the insert of the corresponding panel; the markers represent the median of the ratios, and the lower and upper limits of the error bars indicate the $1^{\text {st }}$ and $3^{\text {rd }}$ quartile, respectively. 

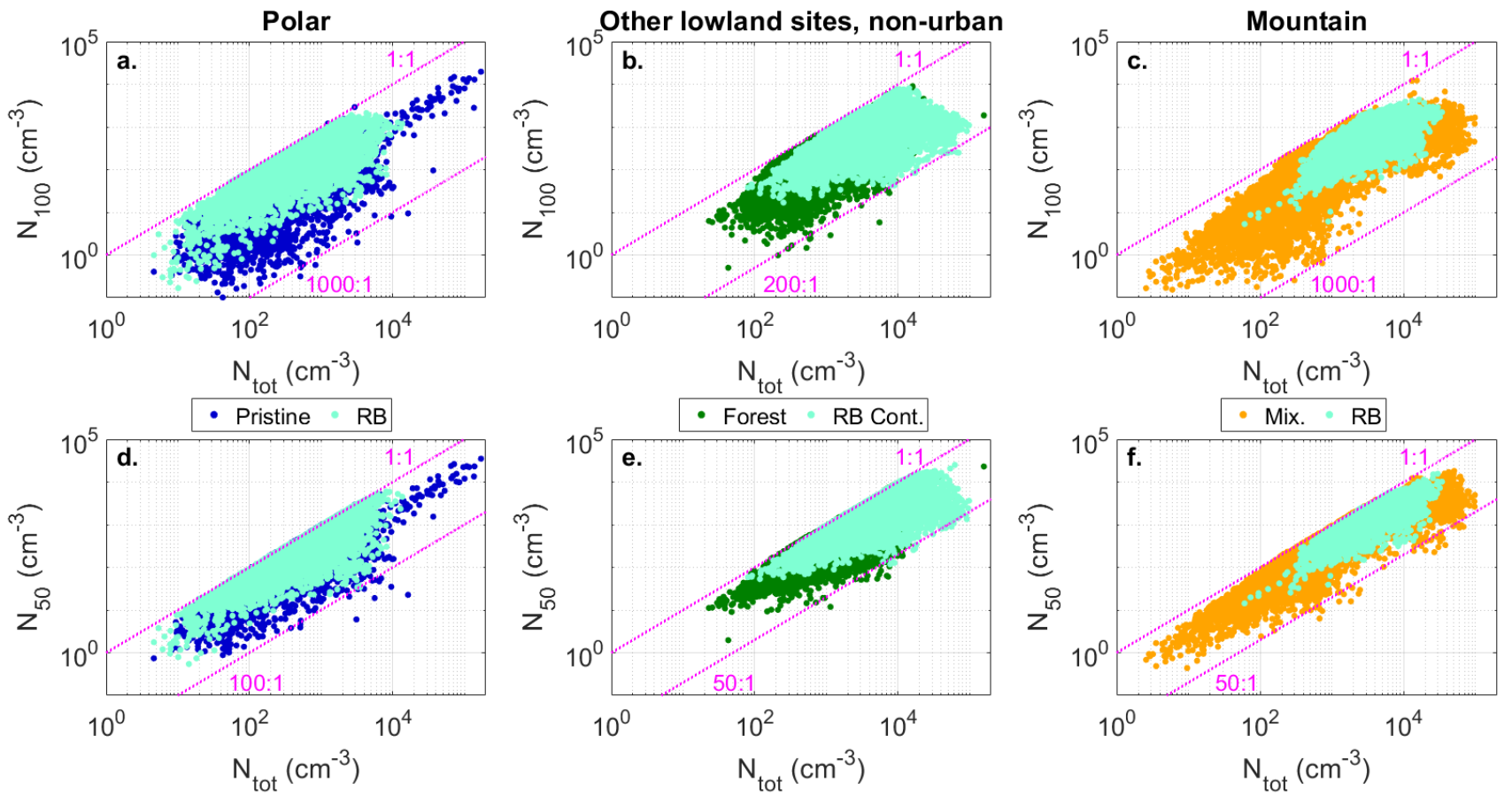

Fig. S9 Scatter plots of $\mathrm{N}_{100}$ (a., b., c.) and $\mathrm{N}_{50}$ (d., e., f.) as a function of $\mathrm{N}_{\text {tot }}$ (hourly averages). The different footprints represented within each station type are highlighted. 
Table S3 Connection between $\mathrm{N}_{50}$, the particle number concentration in the range 50-500 nm, used as an additional proxy for the $\mathrm{CCN}$ population, and $\mathrm{N}_{\text {tot }}$. For each station type and season, the equation of the linear fit performed on the logarithm of the data is reported in the second column, and the corresponding coefficient of determination in the third column. Note that based on corresponding $\mathrm{p}$-values, all correlations were found significant at $95 \%$ confidence level $(\mathrm{p}<0.05)$.

\begin{tabular}{|c|c|c|}
\hline Station type / season & Fit equation & $\mathrm{R}^{2}$ \\
\hline \multicolumn{3}{|l|}{ Polar sites } \\
\hline Year & $\log _{10}\left(\mathrm{~N}_{50}\right)=0.93 \times \log _{10}\left(\mathrm{~N}_{\mathrm{tot}}\right)-0.23$ & 0.76 \\
\hline Winter & $\log _{10}\left(\mathrm{~N}_{50}\right)=0.95 \times \log _{10}\left(\mathrm{~N}_{\mathrm{tot}}\right)-0.24$ & 0.81 \\
\hline Spring & $\log _{10}\left(\mathrm{~N}_{50}\right)=0.70 \times \log _{10}\left(\mathrm{~N}_{\mathrm{tot}}\right)+0.26$ & 0.48 \\
\hline Summer & $\log _{10}\left(\mathrm{~N}_{50}\right)=0.99 \times \log _{10}\left(\mathrm{~N}_{\mathrm{tot}}\right)-0.26$ & 0.66 \\
\hline Fall & $\log _{10}\left(\mathrm{~N}_{50}\right)=0.97 \times \log _{10}\left(\mathrm{~N}_{\mathrm{tot}}\right)-0.32$ & 0.72 \\
\hline \multicolumn{3}{|l|}{ Urban sites } \\
\hline Year & $\log _{10}\left(\mathrm{~N}_{50}\right)=0.87 \times \log _{10}\left(\mathrm{~N}_{\mathrm{tot}}\right)+0.09$ & 0.67 \\
\hline Winter & $\log _{10}\left(\mathrm{~N}_{50}\right)=0.99 \times \log _{10}\left(\mathrm{~N}_{\mathrm{tot}}\right)-0.33$ & 0.77 \\
\hline Spring & $\log _{10}\left(\mathrm{~N}_{50}\right)=0.79 \times \log _{10}\left(\mathrm{~N}_{\mathrm{tot}}\right)+0.39$ & 0.61 \\
\hline Summer & $\log _{10}\left(\mathrm{~N}_{50}\right)=0.73 \times \log _{10}\left(\mathrm{~N}_{\mathrm{tot}}\right)+0.65$ & 0.59 \\
\hline Fall & $\log _{10}\left(\mathrm{~N}_{50}\right)=0.92 \times \log _{10}\left(\mathrm{~N}_{\mathrm{tot}}\right)-0.11$ & 0.69 \\
\hline \multicolumn{3}{|l|}{ Other lowland sites } \\
\hline Year & $\log _{10}\left(\mathrm{~N}_{50}\right)=0.95 \times \log _{10}\left(\mathrm{~N}_{\mathrm{tot}}\right)-0.15$ & 0.71 \\
\hline Winter & $\log _{10}\left(\mathrm{~N}_{50}\right)=1.03 \times \log _{10}\left(\mathrm{~N}_{\mathrm{tot}}\right)-0.40$ & 0.79 \\
\hline Spring & $\log _{10}\left(\mathrm{~N}_{50}\right)=0.90 \times \log _{10}\left(\mathrm{~N}_{\mathrm{tot}}\right)-0.03$ & 0.61 \\
\hline Summer & $\log _{10}\left(\mathrm{~N}_{50}\right)=0.77 \times \log _{10}\left(\mathrm{~N}_{\mathrm{tot}}\right)+0.52$ & 0.55 \\
\hline Fall & $\log _{10}\left(\mathrm{~N}_{50}\right)=1.00 \times \log _{10}\left(\mathrm{~N}_{\mathrm{tot}}\right)-0.33$ & 0.72 \\
\hline \multicolumn{3}{|l|}{ Mountain sites } \\
\hline Year & $\log _{10}\left(\mathrm{~N}_{50}\right)=0.96 \times \log _{10}\left(\mathrm{~N}_{\mathrm{tot}}\right)-0.25$ & 0.86 \\
\hline Winter & $\log _{10}\left(\mathrm{~N}_{50}\right)=0.94 \times \log _{10}\left(\mathrm{~N}_{\mathrm{tot}}\right)-0.29$ & 0.88 \\
\hline Spring & $\log _{10}\left(\mathrm{~N}_{50}\right)=0.95 \times \log _{10}\left(\mathrm{~N}_{\mathrm{tot}}\right)-0.21$ & 0.85 \\
\hline Summer & $\log _{10}\left(\mathrm{~N}_{50}\right)=0.94 \times \log _{10}\left(\mathrm{~N}_{\mathrm{tot}}\right)-0.08$ & 0.85 \\
\hline Fall & $\log _{10}\left(\mathrm{~N}_{50}\right)=0.94 \times \log _{10}\left(\mathrm{~N}_{\mathrm{tot}}\right)-0.26$ & 0.86 \\
\hline
\end{tabular}

